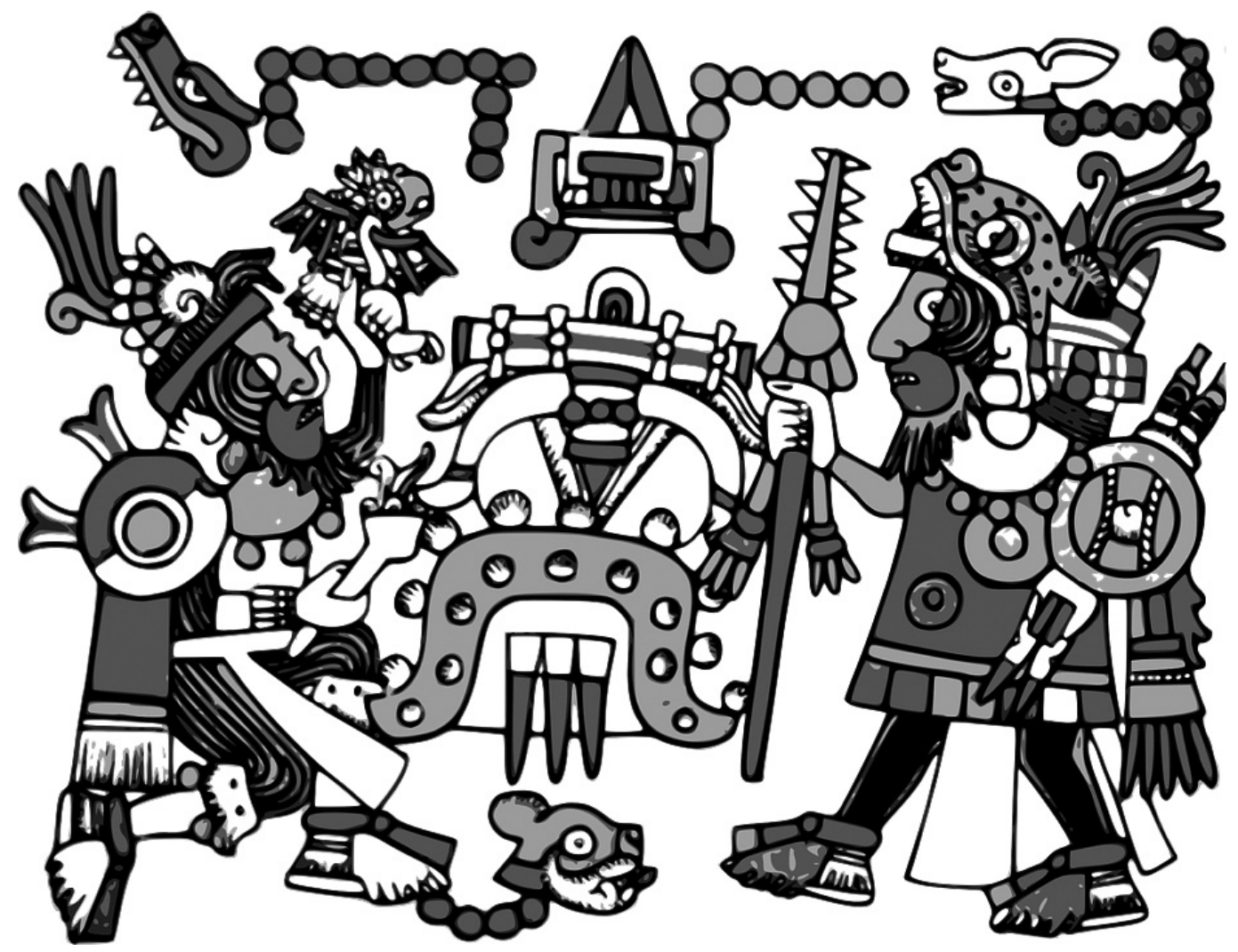

Aztecas. Imagen de dominio público CCO. Tomada de: https://pixabay.com/es/ 


\title{
Tenochtitlan: reflexiones sobre lo mítico en la construcción de la modernidad en América Latina
}

\section{Tenochtitlan: Reflection on myth in the construction of Modernity in Latin America}

Gustavo Hernández Castro Universidad Estatal a Distancia (UNED), Costa Rica

ghernandezc@uned.ac.cr

\begin{abstract}
Resumen
Este artículo pretende explicar la relación existente entre el suceder mítico en la caída de la ciudad de Tenochtitlan a manos de los conquistadores españoles, desde la Visión de los vencidos (León-Portilla, 1992), Crónica Mexicayotl (Alvarado Tezozómoc, 1992) y el suceder imaginario de la novela TENOCHTITLAN. La última batalla de los aztecas (Sánchez, 2009). Se contrastan las narraciones para comprender que desde una visión mítica de acontecimientos históricos (primera y segunda modernidad), se construyen subjetividades, realidades y vivencias sustentadas (testigos históricos) que fundamentan las explicaciones de la caída de un imperio, el desmoronamiento de una civilización completa a manos de extranjeros conquistadores, $y$ en consecuencia la prolongación de un imaginario geocultural del sistemamundo, que caracteriza la modernidad de América Latina.
\end{abstract}

Palabras claves: mito, sistema-mundo, colonialidad, discursos, paradigma planetario

\begin{abstract}
This article aims to explain the relationship between the mythical succession in the fall of the city of Tenochtitlan at the hands of the Spanish conquerors, from the Vision of the Vanquished (León-Portilla, 1992), Crónica Mexicayotl (Alvarado Tezozomoc, 1992) and the Imaginary happening from the novel TENOCHTITLAN. The last battle of the Aztecs (Sánchez, 2009).
\end{abstract}


The narrations are contrasted, to understand that from a mythical vision of historical events (first and second modernity), subjectivities, realities and sustained experiences are built (historical witnesses) that support the explanations of the fall of an empire, the crumbling of a complete civilization at the hands of foreign conquerors, and consequently the prolongation of a geocultural imaginary of the world-system, which characterizes the modernity of Latin America.

Keywords: myth, world-system, colonialism, discourse, planetary paradigm

\section{Introducción}

- Qué relación tiene el surgimiento y

6 la caída de Tenochtitlan en la construcción de la modernidad en América latina? Los aztecas (nahuas migrantes de Aztlán) fueron un pueblo nómada (peregrinos y guerreros) que tardaron unos 260 años para llegar a construir lo que fue la gran ciudad de Tenochtitlan. El desarrollo económico, social y cultural de este imperio fue consecuencia del aporte de grupos o patrias etnogénicas distintas, como los toltecas, huastecas, chichimecas y zapotecos (Girard, 1976).

La ciudad de Tenochtitlan se fundó y organizó en un islote del lago de Texcoco en el año 1325 . Sus pobladores se asentaron en las inmediaciones del lago homónimo. Cuenta la leyenda que durante el año 1325 d.C., el señor de Culhuacan fue invitado a una celebración, para presenciar la trasformación de su hija, en la diosa Yaocíhual; tiempo después, observó a un sacerdote mexica vestido con la piel de su hija; este fue el propósito (sacrifico humano para alimentar al astro sol) de Huitzilopochtli.
Este episodio generó una batalla de los culhuacanos contra los mexicas que se escondieron en el lago, en la cual Cuauhtlequetzqui y Axolohuan (Tenoch) tuvieron la visión de que se encontraban en el centro del universo mexica. En ese centro, se hallaba un nopal y en este, posaba un águila con las alas extendidas que luchaba con una serpiente cascabel (existe otra información que indica que el águila estaba devorando aves de distintos colores), ante este hecho Cuauhtlequetzqui y Tenoch hicieron una reverencia ante el mismo Huitzilopochtli (transformado en águila) que triunfa sobre la serpiente. Tenoch se interna en el lago y luego aparece con un mensaje de Tláloc (dios del agua): ya llegó mi hijo Huitzilopochtli, esta es su casa. Es el único a quien debe quererse y permanecerá conmigo en este mundo. De esta forma, al grupo de mexicas se les informa que habían llegado al lugar indicado “(...) Allí llegaron entonces. Por esto se llama ahora Tenochtitlan Cuauhtli itlacuayan: dónde está al águila que devora en el nopal sobre la piedra" (León-Portilla, 2004, p. 119).

Cervera (2008) señala que la historia del pueblo Azteca se divide en dos periodos. 
El primero comprende de 1111 d.C. (salida de los mexicas de Aztlán), incluye la fundación de la ciudad México-Tenochtitlan en 1325 hasta el año de 1428. El segundo engloba la etapa imperial (periodo azteca tardío) y se caracterizó por la conformación de la Triple Alianza y la expansión de los mexicas con Moctezuma Ilhuicamina hasta la caída de la ciudad en 1521 .

Con la caída de la ciudad de Azcopolzalco, ubicada en la orilla oeste del lago de Texcoco en 1426, consecuencia de la muerte de Tezozómo (gobernante tepaneca), y el debilitamiento de las alianzas existentes que mantenía este último, la triple alianza conformada por Texcoco, Tlacopan y Tenochtitlan toma el dominio del valle de México, a partir de 1430.

Fue un imperio próspero y con gobernanza; organizado económica, social, religiosa y militarmente. Se expandió en lo que hoy se conoce como los estados de México, Veracruz, Oaxaca, Chiapas, costa de Guerrero, Hidalgo y parte de Guatemala. Para inicios de 1500, Tenochtitlan se había convertido en la principal ciudad; esta fecha coincide con el liderazgo de Moctezuma Xocoyotzin, quien gobernó entre 1502 y 1520 , y el último periodo de Cuachtláhuac (1476 y 1520), señor de Iztapalapa quien gobernó 80 días, sucedido por Cuauhtémoc (1501-1520) en 1520, un año antes de la llegada de Hernán Cortés Monroy Pizarro Altamirano (1485-1547) a la ciudad de Tenochitlan.

La llegada de los españoles al nuevo mundo tiene relación directa con la primera modernidad y subjetividad que se comienza a gestar en el siglo XV (último siglo de la Edad Media), en términos de unidades geoculturales y posteriormente en cuestiones geohistóricas y geoeconómicas; y con la construcción de un mito legitimado por discursos aristocráticos cristianos sobre la limpieza de sangre; mentalidad que se impregna desde una clasificación poblacional ${ }^{1}$ para la instauración de un sistemamundo occidentalizado y en el que las nuevas tierras descubiertas son la prolongación del europeo blanco y de la cultura cristiana (Mignolo, 1998).

$\mathrm{Al}$ implantarse el eurocentrismo (dominio occidental) como una realidad mítica, a partir del descubrimiento de América, y posicionarse este como mito durante más de cinco siglos, cambia el significado mundial, lo que llama Dussel (1995) paradigma planetario, en el sentido de que todos los fenómenos que atravesó Europa, según este autor, como lo fueron el descubrimiento de América, la Reforma protestante, la Revolución Francesa, la Revolución científica, el Renacimiento italiano, entre otros, se deben visualizar como episodios mundiales, a partir de los cuales Europa es concebida como centro en el sistemamundo moderno colonial (Dussel, 1994). En otras palabras, los conocimientos

1 La distribución geográfica ideada por Heródoto (484425 a.C.) establecía una división territorial en la cual Europa era el centro del poder y conocimiento y, por lo tanto, sus pobladores eran los civilizados; seguidos por Asia y África. Por su parte, los pensadores cristianos de la Edad Media establecen a partir de esta clasificación y del relato del libro del Génesis, en el cual Noé distribuye el mundo a sus hijos: Jafet (Europa), Sem (Asia) y Cam (África) con la finalidad de propagar el dogma unitario cristiano de la creación del ser humano. Lo anterior para legitimar un discurso que permitiría acoger el Nuevo Mundo como la prolongación de la Ciudad de Dios, es decir, Europa y más específicamente, España, representante del blanco cristiano y europeo. 
producidos en las periferias, en este caso, América, no son considerados como tales, se catalogan como conocimientos no científicos e innecesarios. En consecuencia, con la llegada de los españoles y portugueses al Nuevo Mundo, estos no tuvieron reparo en destruir todo lo que se les colocaba a su paso $^{2}$, simultáneamente instituyeron a la fuerza dos idiomas y una religión; incluida la limpieza de sangre y la superioridad de un conocimiento sobre otro y en este transitar, la instauración de una nueva subjetividad, es decir, un nuevo ser humano (superioridad étnica y cognitiva).

Así pues, la superioridad étnica, manifestada en la limpieza de sangre, tiene que ver con el imaginario colonial de la blancura, que no tenía nada que ver con el color de la piel (blanca) sino con el "imaginario cultural tejido por creencias religiosas, tipos de vestimenta, certificado de nobleza, modo de comportamientos y forma de producir conocimientos" (Castro-Gómez 1997, p.68).

\section{Lo mítico}

Aquí se dice, se nombra (el) cómo vinieron a llegar, vinieron a entrar los ancianos que se dice, se nombra los "teochichimecas", gente de Aztlan, mexicanos chicomoztoquenses, cuando vinieron a buscar tierra, cuando vinieron a merecer tierra, aquí en la gran población ciudad de México Tenochtitlan. Su lugar de fama, su lugar de ejemplo, el lugar de asiento del "tenochtli", dentro del agua, el lugar donde el águila se yergue, el lugar donde grita el águila, el lugar donde se extiende el águila,

2 Basta con leer las crónicas de Bartolomé de las Casas, entre otros relatos, para conocer el trato que recibían los nativos por parte de los blancos europeos. el lugar donde come el águila, el lugar donde es desgarrada la serpiente, el lugar en donde nada el pez, el agua azul, el agua amarilla, el lugar de entronque, el lugar del agua abrasada, allá en el ¿brazalete? de plumas, dentro de los tules, dentro de los carrizos, el lugar ¿brazalete? De plumas preciosas, que está en el tular, en el carrizal; el lugar de reunión, de espera de las diversas gentes de los cuatro puntos cardinales, al que llegaron a asentarse los trece "teochichimecas", quienes se asentaron miserabilísimamente cuando llegaron. (Hernando Alvarado ${ }^{3}$ )

... y en nuestro Padre Horizonte, donde se enmarcaba un volcán cubierto de nieve, lanzando humo esa mañana... Y más allá de allá, el lago Texcoco, dividido por el gran dique que impedía a sus salobres juntarse con las dulces de nuestra hermana laguna de Tenochtitlan.

Y así como después se marcarían en rojo los nombres de los invasores en el rostro de nuestros guerreros, en el hombro de nuestras vírgenes, en la pantorrilla de nuestros niños para convertirlos en esclavos; así, en un rojo vivo, vi aparecer unas letras sobre el azul del lago que decían: Ehecatl Quechollt.

Y escuché un grito de mujer, también con palabras en rojo, que las repetía. Esa mañana fue el 8 de noviembre de 1519 , en el habla de los visitantes, llamados por otros mensajeros de nuestro señor Quetzalcóatl, hijos de los dioses y dioses ellos mismos. Volví la mirada hacia la gran ciudad de Tenochtitlan, tan reunida por los siglos, tan hermosa... y

3 Hernando Alvarado Tezozomoc (1525-1610). Escribió la Crónica Mexicayotl. Nieto de Moctezuma Xocoyotzin II. (p. 3). 
lloré. Era nuestro último día de libertad. Porque ésa fue la voluntad de nuestros dioses. (José León Sánchez ${ }^{4}$ )

En el reinado de Izcóalt (1381-1440), cuarto tlatoani de los mexicas quien gobernó de 1427 a 1440, y de su sobrino Tlacaelel (1398-1480), supremo sacerdote quien ejerció el cargo de tlacatecatl de 1418 a 1478 , los mexicas terminaron de consolidar un imperio militar-religioso, y con ello, reescribir una nueva historia. Para esto, borran de sus relatos y registros históricos todas las menciones, las cuales narran que sus antepasados eran pueblos migrantes y débiles, bajo la consigna de que los mexicas nunca fueron vasallos de nadie y de nada. A partir de ese momento, la nueva historia mexica sería recordada por grandes victorias producto de su desarrollo económico, social y cultural. Esta historia sería escrita en Tenochtitlan como el centro del cosmos y desarrollada bajo las guerras floridas y de conquista.

En este contexto, las dos narraciones (posterior al aparado titulado Lo mítico) pretenden explicar la génesis de una ciudad y, al mismo tiempo, el origen de su caída. Un relato es visto desde dos documentos historiográficos (Miguel León-Portilla [1926-] y Hernando Alvarado Tezozómoc [1520 y 1530-1610]), el otro es una narración literaria (José León Sánchez [1929]). Al leer los pasajes, surgen las siguientes preguntas: ¿existen similitudes o diferencias en ambas narraciones?; ¿será que el elemento mítico se incrusta en las letras y la historia, para explicar una realidad marcada de una modernidad: la conquista de

4 Sánchez, 2009, p. 20. un nuevo mundo para dominarlo?, como lo señala Sánchez (2009):

Desde ese momento, la cuenta del tiempo caminó por otro lugar, como si de repente los pájaros empezaran a volar por debajo de la tierra (...) No sé lo que dirá la otra historia. La que empezaron a contar los que llegaron hasta nuestra ciudad en mitad de los rayos del sol de la mañana. Creo que ellos escribieron lo primero que vieron. Lo primero que apuntaron en sus libros fue nuestro rostro. Sus ojos se quedaron en nuestros ojos. Y así fue, ya que así siempre empieza la historia. (p. 20-21)

Por su parte, en relato de Alvarado (1992), capítulo 108 , último párrafo, indica:

(...) Señor rey, no es verdad que han venido no sé qué gentes habían llegado a las orillas de la Gran Mar, los cuales andaban pescando con cañas y otros con una red (...) y las carnes de ellos muy blancos, más que nuestras carnes, excepto que todos lo más tienen barba larga y cabellos hasta la oreja les da. (s.p.)

De la siguiente forma lo reseña León-Portilla (1992):

Los nigrománticos en realidad no pudieron dar respuesta. Pero, en cambio, por ese tiempo apareció un pobre macehual (hombre del pueblo), venido de las costas del Golfo con las primeras noticias de la llegada de unas como "torres o cerros pequeños que venían flotando por encima del mar". En ellos venían gentes extrañas "de carnes muy blancas, más que nuestras carnes, todos los más tienen barba larga y el cabello hasta la oreja les da..." Tal noticia despertó la angustia de Moctezuma (...). (p. 18) 
Sabemos que en la Visión de los vencidos de León-Portilla (1992), los primeros trece capítulos describen hechos sucedidos antes de la llegada de los españoles a las costas del Golfo de México, hasta la caída de Tenochtitlan en manos de los conquistadores. En los dos últimos capítulos, se narra un epílogo acerca de la conquista, escrito en 1528 por testigos anónimos de Tlatelolco: Una visión de conjunto. Relación de la conquista (1528) por informantes anónimos de Tlatelolco, que termina con cuatro cantos tristes de la conquista: Se ha perdido el pueblo mexica; Los últimos días del sitio de Tenochtitlan; La ruina de tenochcas y tlatelolcas y La prisión de Cuauhtémoc.

No es objetivo de este artículo realizar una hermenéutica de los textos de la Visión de los vencidos, respecto a si los hechos sucedidos y los testimonios dados corresponden a una lectura histórica o historiográfica de los acontecimientos registrados. Lo que sí es valioso es considerar los textos a la luz de un encuentro o vivencia mítica sobre la explicación de acontecimientos históricos, los que guardan relación con la llegada de los españoles a Tenochtitlan y la nueva subjetividad que se incorpora tanto en los españoles victoriosos como en los mexicas vencidos.

Así pues, en este contexto histórico-mítico, y en lo más hondo de su corazón, Moctezuma II estaba convencido de que los ocho presagios, anunciados diez años antes de la llegada de los nuevos visitantes, era el fin de su amada Tenochtitlan. Estos presagios funestos iniciaban con "una espiga de fuego" visible en el cielo $\mathrm{y}$, con ella, las siete restantes profecías.
León-Portilla (1992) describe detalladamente los presagios:

Primero: "diez años antes de venir los españoles (...) una como espiga de fuego, una como llama de fuego, una como aurora: se mostraba como si estuviera goteando, como si estuviera punzando en el cielo" (p. 22).

Segundo: "que sucedió aquí en México: por su propia cuenta se abrasó en llamas, se prendió en fuego: nadie tal vez le puso fuego, sino por su espontánea acción ardió la casa de Huitzilopochtli. Se llamaba su sitio divino, el sitio denominado" Tlacateccan" ("Casa de mando") (p.22).

Tercero: "fue herido por un rayo un templo. Sólo de paja era: en donde se llama "Tzummulco". El templo de Xiuhtecuhtli. No llovía recio, solo lloviznaba levemente".

Cuarto: "cuando había aún Sol, cayó un fuego. En tres partes dividido: salió de donde el Sol se mete: iba derecho viendo a donde sale el Sol: como si fuera brasa, iba cayendo en lluvia de chispas. Larga se tendió su cauda; lejos llegó su cola. Y cuando visto fue, hubo gran alboroto: como si estuvieran tocando cascabeles". (p. 23).

Quinto: "hirvió el agua: el viento la hizo alborotarse hirviendo. Como si hirviera en furia, como si en pedazos se rompiera al revolverse. Fue su impulso muy lejos, se levantó muy alto. Llegó a los fundamentos de las casas: y derruidas las casas, se anegaron en agua. Eso fue en la laguna que está junto a nosotros". (p. 23).

Sexto: "muchas veces se oía: una mujer lloraba; iba gritando por la noche; andaba dando grandes gritos: $-i$ Hijitos míos, pues ya tenemos que irnos lejos! 
Y a veces decía: -Hijitos míos, ¿a dónde os llevaré? (p. 23)

Séptimo: Muchas veces se atrapaba, se cogía algo en redes. Los que trabajaban en el agua cogieron cierto pájaro ceniciento como si fuera grulla. Luego lo llevaron a mostrar a Motecuhzoma, en la Casa de lo Negro (casa de estudio mágico). (p. 23).

Octavo: "muchas veces se mostraban a la gente hombres deformes, personas monstruosas. De dos cabezas pero un solo cuerpo. Las llevaban a la Casa de lo Negro; se las mostraban a Motecuhzoma. Cuando las había visto luego desaparecían. (p. 24).

La figura 1 ilustra los presagios funestos:

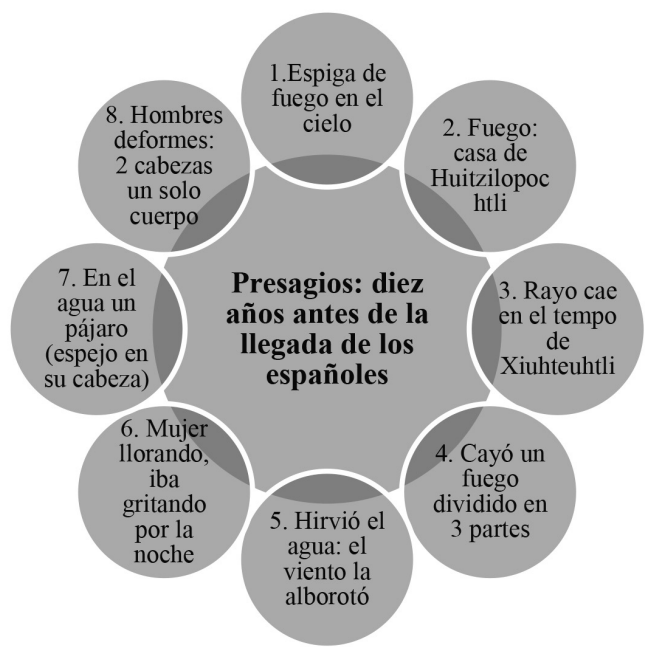

Figura 1. Los 8 presagios de los informantes de Sahagún

Fuente: elaboración propia a partir de libro de LeónPortilla (1992)

Así, pues, desde los inicios, con las migraciones del pueblo mexica y la historia construida (desde el año 1111 d.C.) se anunciaba la llegada de los dioses, en este caso coincidencia del arribo de los españoles, mediante
8 presagios que dictaban nuevos acontecimientos, interpretados a la luz de fenómenos naturales que avisaban el retorno del dios Quetzalcóatl y al cual el tatloani debía preparase para recibir al dios prometido.

Al respecto, Sánchez (2009) narra lo siguiente:

MOCTEZUMA Xocoyotl escuchaba atentamente toda la narración y analizaba el enorme sentido que para un hombre tan religioso como él significaba la visita de gente blanca hasta las tierras del cacao, de las flores, de la sal, donde se multiplicaba el algodón. Acorde con su investidura de señor de mar a mar, no debía manifestar ninguna clase de sentimiento y trataba de mantener su postura de señor Ceñudo, pero en esa oportunidad no lo lograba. Lo que escuchaba era para él lo más parecido al regreso de los hijos del Sol, como tantas veces lo había leído en las páginas de los libros sagrados de templo de Quetzalcóatl. (p. 41).

Así las cosas, el pasado (inicio de Tenochtitlan) se construye con el arribo de los trece teochichimecas; gente de Aztlan, que llegaron buscando tierras. Ese mismo pasado, se presenta como un futuro "quienes se asentaron miserabilísimamente cuando llegaron" (Alvarado, 1992, p, 4); pasado que Izcóalt y Tlacaelel borraron en el presente, con el propósito de que esa historia no se escuchase. Por su parte, los presagios son como elementos míticos de lo que acontecerá en el futuro (León Portilla, 1992). No obstante, el presente visto por Moctezuma II, al observar desde el templo la llegada del conquistador: "Hernán Cortés y sus capitanes pararon en seco a sus caballos y con una intensa alegría en sus ojos miraron, por primera vez, a lo 
lejos, la gran ciudad de México Tenochtitlan” (Sánchez, 2009, p. 131).

La siguiente figura muestra esa relación dialéctica:

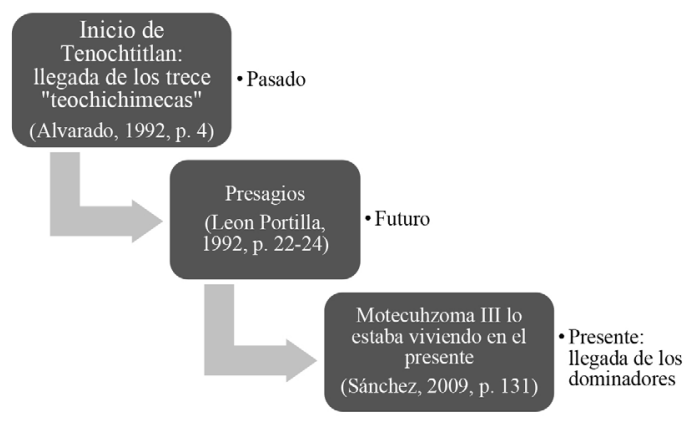

Figura 2. Relación dialéctica: pasado, futuro y presente.

Fuente: elaboración propia a partir de los textos de Alvarado y Sánchez

En síntesis, se puede afirmar que la construcción de la realidad mítica en América Latina se da con la llegada de los españoles al Nuevo Mundo, pero es con el arribo de Cortés y la caída de Tenochtitlan, que tornaron miserable el presente ${ }^{5}$; desde el pasado en los orígenes de los teochichimecas y su salida de Aztlan ${ }^{6}$ y el futuro (493 años después) ${ }^{7}$. En el transcurso de estos siglos, distintas generaciones han presenciado y participado de las consecuencias de esa modernidad impuesta en América Latina.

\section{Lo real}

Para comprender el suceder real sobre la conquista y caída de Tenochtitlan, y su

5 1519, arribo de los españoles a costas de Veracruz; 1520, asesinato de Moctezuma III y 1521, caída de México Tenochtitlan.

61111 d.C., año de la salida de los mexicas de Aztlan.

7 El colonialismo impuesto desde la primera modernidad y que se acentúa con la segunda modernidad en América Latina. relación con el devenir de América Latina, a continuación, se describen tres acontecimientos claves (ver figura 3):

- Hernán Cortés ingresa a Tenochtitlan el 8 de noviembre de 1519, apoyado por los tlaxcaltecas. Moctezuma II los recibe y hospeda en el templo Axayácat $1^{8}$.

- El mito establece que había llegado el dios Quetzalcóatl9 (serpiente emplumada) y, en consecuencia, Moctezuma $\mathrm{II}^{10}$, les ofrece alojamiento.

- El 13 de agosto de 1521, se entrega Cuauhtémoc a los españoles; con este acontecimiento, los mexicas se rinden y huyen de la ciudad (cayó desde el cielo un remolino de fuego: el último presagio sobre el final de la ciudad

8 Axayacatl es el templo del padre de Moctezuma.

9 Secretaría de Educación Pública de México (1988: 26) “... el símbolo serpiente emplumada, ligado a Itzam $\mathrm{Na}$, aparece en el área maya desde fines del periodo Preclásico (2000 a.C. a 300 d.C.) representando la fertilidad. Las cualidades unidas del ave y la serpiente constituyeron en el mundo mesoamericano el símbolo religioso por excelencia, pues parece haber representado, además del principio vital cósmico que da origen al mundo (la energía fecundante de los mitos cosmogóni$\cos$ ), la fertilidad del cielo, o sea, la lluvia, que para los pueblos agricultores es la base de la subsistencia (fig. 2). Para los nahuas, en el altiplano central, la serpiente emplumada tuvo también un sitio de primera importancia entre las manifestaciones de lo sagrado, y se llamó Quetzalcóatl. Con la llegada de grupos nahuas al área maya a principios del Posclásico, Quetzalcóatl se identificó con la serpiente emplumada ya existente desde siglos antes, y fue venerado principalmente en Chichén Itzá con el nombre de Kukulcan, que también significa serpiente emplumada".

10 Moctezuma III muere en 1520: la historia señala dos versiones. La primera es que Cortés liberó a Moctezuma de su encarcelamiento y le solicitó que hablara con su pueblo para que la guerra cesase. Ante esto, el pueblo le comenzó a arrojar piedras hasta que una de ellas lo impactó en la cabeza (a los 3 días murió). La segunda versión relata que los españoles lo asesinaron. 


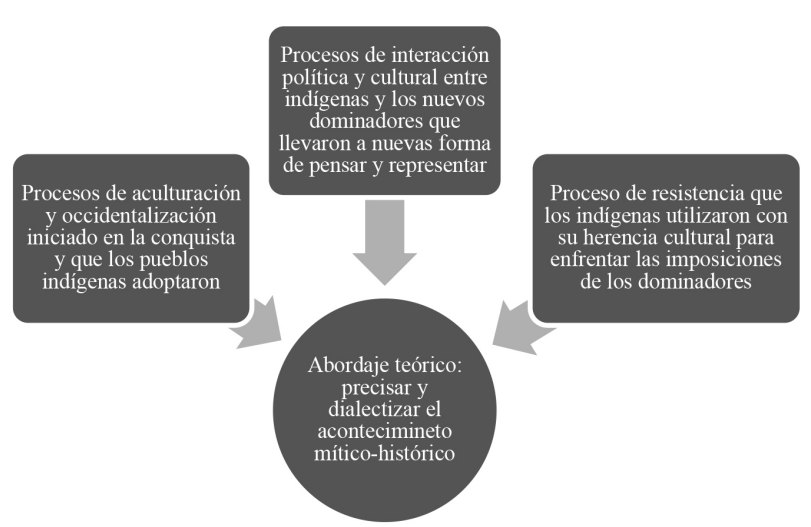

Figura 3. Posturas teóricas para el abordaje mítico-histórico Fuente: elaboración propia a partir del trabajo de Navarrete (2007).

de Tenochtitlan). Se debe recordar que con la muerte de Moctezuma II, Cuauhtémoc es elegido el nuevo tlatoani en 1520, un año antes de la toma de la ciudad de Tenochtitlan por parte de Hernán Cortés.

Navarrete (2007) señala la existencia de tres premisas para el abordaje teórico del suceder real (postura histórica):

- Procesos de aculturación y occidentalización: en la cual los indígenas adoptaron todas las prácticas accidentales modificando de manera irreversible sus propias tradiciones milenarias con la llegada de los conquistadores.

- Procesos de resistencia: por ejemplo, el sincretismo religioso utilizando símbolos indígenas para preservar su cultura, pero que al mismo tiempo sirviera para que los españoles conquistadores pensaran que estaban siendo adoctrinados con las nuevas formas de pensamiento (por ejemplo la figura de la Malinche). O bien, entre los mismos pueblos indígenas, por ejemplo, los distintos tipos de sacrificios humanos en Tenochtitlan, en los cuales se puede destacar el sacrifico gladiatorio.

- Procesos de interacción política y cultural: procesos que se dan cuando los españoles y los indígenas intercambian conocimiento y prácticas sociales que con el tiempo se transforman en nuevos saberes y formas de pensar que al interrelacionarse son explicadas y entendidas según la visión de los vencidos o de los conquistadores. En otras palabras, son discursos que pueden ser vistos desde la óptica conquistadora (españoles) o bien, desde la perspectiva de los conquistados, que servirán para salir de la posición de pueblos sumisos y subyugados; el caso del pueblo tlaxcalteca, que aprovechando la llegada de Cortés puede liberarse del dominio de la ciudad de Tenochtitlan, asumiendo así un papel de liberación, sin romper con sus propias tradiciones milenarias pero sí reelaborándolas a partir de la llegada de los conquistadores.

No es pretensión de este artículo tomar postura y explicar al detalle cada una de las tres direcciones señaladas. No obstante, el siguiente texto, es un ejemplo en el cual se esbozan tales premisas o direcciones enunciadas (Sánchez, 2009):

(...) En las puertas de la ciudad se preparaba un altar dedicado a San Francisco de Asís. ¿Quién es San Francisco de Asís? Un hombre blanco que amaba los pájaros, a las mariposas, que se quitaba los huaraches para que sus pies no 
hirieran las piedras del camino (...) Dador de bien. Dador de bondad. Un poco parecido a nuestro señor Quetzalcóatl. San Francisco de Asís fue pintado sobre una tela blanca de algodón, la cual después fue barnizada por uno de los famosos pintores de Texcoco. (p. 423)

Como se puede apreciar, las tres posturas reflejan un acercamiento al punto de partida: la coincidencia de la llegada del dios Quetzalcóatl con el arribo de los españoles a las costas mexicanas: el mito (futuro- pasado: llegada de los trece teochichimecas) como una posible interpretación de la realidad (presente-pasado: ingreso de Cortés a Tenochtitlan el 8 de noviembre de 1519; muerte de Moctezuma II en 1520 y la entrega de Cuauhtémoc a los españoles el 13 de agosto de 1521).

De este modo, la llegada de los españoles y portugueses a la América india no es una circunstancia aislada, es producto de discursos y posturas que se sostienen y fundamentan en distintos lugares de una Europa en reconstrucción, que inician con la primera modernidad (XV) y se termina de consolidar en el siglo XVIII al conformar una red planetaria con el propósito de imponer un sistema-mundo colonial del proyecto científico de la Ilustración y del proyecto colonial europeo (futuro-presente).

Al respecto, Sánchez (2009) nos regala una metáfora (sucedida el 13 de agosto de 1521) de la rendición de los mexicas, dejando, así, abierto el camino y la luz de lo que es hoy la América Latina:

¿Rendirnos? ¿Rendirnos ahora cuando ya hemos comido zacate en los caminos al amanecer? Hoy, esta mañana, los niños y las mujeres enfermas han salido a buscar los retoños del zacate... Ya tenemos una esperanza. ¿Por qué rendirnos? Ya nos hemos comido las semillas del colorín y sus cáscaras. Y nos hemos alimentado de cuero... pedazos de cuero, plantas de lirios... Hemos bebido en los charcos de la lluvia... Un día se nos terminaron las mazorcas de maíz... se han muerto los señores de la ciudad en las cuatro distancias, Teopan, Moyotlan, Aztacalco, Cuepopan... De rendirnos nos espera la miseria de los blancos... Ya lo dijo antes nuestro señor Cuauhtémoc: "La miseria no tapará las goteras del llanto sobre nuestros hijitos, sobre nuestras hijitas..." Pueden rendirse los hombres. ¡Ya! Las mujeres no vamos a rendirnos... Si abandonamos este momento en que retoñan los tallos de la hierba, ¿quién ha de cuidar a nuestros dioses de la Luna, del Sol, del Agua? Si abandonamos nuestra lucha hoy, mañana la historia dirá: miren, ahí va esa mujer tenocha, la hija de la hija de la que se orinó entre los itzcuintlis... ahí va la que lleva la miseria, la que no tuvo el valor, la que corrió frente a los perros, la que no fue digna hermana de la guerrera Águila, de la guerrera Coyote, de la guerrera Ocelotl, de la guerrera Jaguar... ¡Rendirnos nunca! ¡Nunca! Si los itzcuintlis ganan esta guerra a nosotros nos van a dedicar mañana para el oficio de la putas... y mañana andaremos buscando por todas partes lo que hoy no hemos perdido (...) Si perdemos esta guerra... solamente nos usarán para hacer cacharros... nadie escuchará nunca más las palabras mexicanas... ya no seremos un número como las juncias del lago... Ya no seremos garzas... ya no podremos volar... Llegará la iniquidad, el vicio... Seremos herrados todos en la cara... (p. 416-417). 


\section{Conclusión}

Al analizar lo textos señalados en la articulación discursiva de este artículo, encontramos evidencias de la existencia de una realidad mítica (suceder imaginario) que se interrelaciona con el suceder real de los acontecimientos acaecidos en Tenochtitlan; desde la llegada de los trece teochichimecas (el lugar de asiento del "tenochtli"), hasta el arribo de los conquistadores.

Lo anterior lo sustento en una relación dialéctica (espiral) de pasado, presente y futuro en un constante movimiento sin final, el cual permite la incorporación del suceder imaginario (mito) con acontecimientos históricos; posiblemente, para justificar una posición hegemónica (visión desde el vencedor), para tratar de explicar una realidad esperada y venida del Este (visión de los vencidos), o bien como una forma de expresión práctica de realización, señalada por Navarrete (2008) como una capacidad de etnogénesis para defender o modificar la vivencia cotidiana de una realidad imposible de cambiar.

Tal y como lo señala De la Garza, refiriéndose al pueblo maya, en la introducción del libro CHILAM BALAM DE CHUMAYEL (1988):

Las narraciones de la Conquista española destacan por su dramatismo, lo que nos corrobora que los libros se escribieron con una actitud defensiva y con el afán de afirmar las antiguas creencias y "desterrar el cristianismo", así como los españoles pretendían "desterrar la idolatría". Vemos en estos fragmentos, dolorosos lamentos por la llegada de los españoles, indignación y desprecio ante su actitud rapaz, y ante su lujuria, que se expresa con el símbolo de la flor de mayo. Estos temas revelan, así, las preocupaciones centrales de los mayas de Chumayel que quisieron expresarlas por escrito para que no fueran olvidadas por sus descendientes. (p. 10)

Tenochtitlan y lo que representa su caída a manos de los conquistadores españoles volvió miserable un presente ("Hernán Cortés y sus capitanes pararon en seco a sus caballos (...) miraron, por primera vez, a lo lejos, la gran ciudad de México Tenochtitlan"), el cual fue pasado, en los orígenes, cuando los trece teochichimecas (se asentaron miserabilísimamente); y un futuro (495 años después) lleno de miseria para la gran mayoría de la población de América Latina, con $46 \%{ }^{11}$, que no tiene cómo satisfacer sus necesidades básicas.

Como se ha señalado, la llegada de los españoles al Nuevo Mundo y la caída de Tenochtitlan tienen relación directa con la primera modernidad que se comienza a gestar en el siglo XV (último siglo de la Edad Media) y la transformación de un nuevo sujeto, que se explica en procesos sistémicos de unidades geoculturales, geohistóricas y geoeconómicas. En todo caso, para Moctezuma III, los presagios ya no solo eran presagios, eran una realidad $\mathrm{y}$, por tanto, 10 años antes de la llegada de los españoles, el pasado se convirtió en un presente, $y$, en poco tiempo, dos formas distintas de pensar y actuar que se enfrentarían para construir un futuro marcado de colonialidad (sistema-mundo).

11 Según datos de la CEPAL 2015. Recuperado de: http://www.hoy.com.ec/noticias-ecuador/pobreza-enamerica-latina-rebasa-las-estadisticas-117017.html (3 de marzo de 2015). 
La modernidad trajo consigo, para Tenochtitlan y para nuestra América, el derrumbe de siglos de construcción cultural, de cimentación de prácticas comunitarias y de una cosmovisión integral del ser humano como parte de un universo o geografía cósmica; en contraste, se aprecia una visión de suicidio colectivo y de un modelo de dominación que Dussel (1994) denomina "sistema-mundo moderno colonial" que existe, entre otras cosas, para desintegrar y eliminar pensamientos alternativos posibles.

Ahora bien, cabe la pregunta: ¿qué significado tiene Tenochtitlan y cómo actúa la subjetividad en la modernidad latinoamericana? Quizás y solo quizás la instauración del sistema-mundo moderno colonial ha transformado la subjetividad latinoamericana, es decir, es un sujeto (retorno al sujeto) que crea y recrea la ética, en la disyuntiva de una ética normalizadora o absoluta, donde existe un individuo capaz de desdoblarse frente a los demás con eterna violencia en el plano de un pensamiento-acción como praxis de la muerte.

\section{Referencias}

Alvarado, H. (1992). Crónica Mexicayotl. México: Editorial UNAM.

Castro-Gomez, S. (1997). La hybris del punto. Ciencia, raza e ilustración en la Nueva Granada (1750-1816). Colombia: Pontificia Universidad Javeriana.

Cervera, M. (2008). Breve historia de los Aztecas. Madrid: Nowtilus, S.L.

Dussel, E. (1994). 1492 El encubrimiento del otro. Hacia el origen del "mito de Modernidad”. La Paz: Plural Editores.
Dussel, E. (1995). Introducción a la filosofía de la liberación. Bogotá: Editorial Nueva América.

Girad, R. (1976). Historia de las civilizaciones antiguas de América. España: Ediciones ISTMO.

León-Portilla, M. (1992). Visión de los vencidos. México: Editorial UNAM.

León-Portilla, M. (2004). En torno a la historia de Mesoamérica. Tomo II. México: UNAM.

Mignolo, W. (1998). The Darker Side of the Renaissance. Literacy, Territoriality and Colonization. United Estate of America: The University of Michigan Press.

Navarrete, F. (2007). "La Malinche, la Virgen y la montaña: el juego de la identidad en los códices tlaxcalteca". Revista Historia. Número 2, Volumen 26. São Paulo.

Sánchez, J. L. (2009). TENOCHTITLAN. La última batalla de los aztecas. México: Editorial Grijalbo.

Secretaria de Educación Pública de México. (1988). Libro de Chilam Balam de Chumayel. México: SEP Cultura. 
